\title{
Neglected Food Bubbles: The Espresso Coffee Foam
}

\author{
Ernesto Illy • Luciano Navarini
}

Received: 13 December 2010 / Accepted: 23 March 2011 /Published online: 30 March 2011

(C) The Author(s) 2011. This article is published with open access at Springerlink.com

\begin{abstract}
Coffee beverage known as espresso, must be topped by a velvety thick, reddish-brown foam called crema, to be considered properly prepared and to be appreciated by connoisseurs. In spite of the relevant role played by crema as a quality marker, espresso coffee foam has not yet been the subject of detailed investigations. Only recently, some aspects of the Physics and Chemistry behind the espresso coffee foam have attracted the attention of scientists. In addition to sharing several characteristics with other food foams like beer foam, for instance, the espresso coffee foam may contain solid particles (minute coffee cellwall fragments), it is subjected to a remarkable temperature gradient and its continuous phase is an oil in water emulsion rendering it a very complex system to be studied. Moreover, in the typical regular espresso coffee cup volume (serving) of 25-30 mL, crema represents at least $10 \%$ of the total volume, and this is a limitation in obtaining experimental data by conventional instruments. The present work is aimed at reviewing the literature on espresso coffee foam. The traditional espresso brewing method will be briefly described with emphasis on the steps particularly relevant to foam formation and stabilization. In addition to present up-dated experimental data on surface properties at solid/ beverage and air/beverage interface, recent advances on the espresso foam formation mechanism, as well as on foam stability, will be critically examined. The key role played by carbon dioxide generated by roasting and the effects of low and high-molecular-weight coffee compounds in
\end{abstract}

Ernesto Illy (Deceased) - July 18, 1925-February 3, 2008

E. Illy $\cdot$ L. Navarini $(\bowtie)$

Illycaffè S.p.A,

Via Flavia 110,

Trieste 34147, Italy

e-mail: luciano.navarini@illy.com promoting/inhibiting the espresso coffee foam will be discussed and emphasized.

Keyword Espresso coffee $\cdot$ Foam $\cdot$ Crema $\cdot$ Interfacial properties

\section{Introduction}

Espresso coffee extraction is the most common brewing method in Italy and it is increasingly becoming very popular in many other countries around the world, where more than 50 million cups of espresso are consumed every day. ${ }^{1}$ Differently from other brewing techniques, conditions normally used to brew espresso coffee enhance several surface tension-related phenomena such as foam formation and stabilization. In spite of the relevant role played by foam in assessing the beverage quality, no systematic chemical and physical studies have been devoted to better understand this complex system. Espresso foam has often been considered a sort of magic event with its fate linked to the experience of a skilled barista (coffee bar technician) instead of being the result of Chemistry and Physics. Unfortunately, this situation has created various ingrained beliefs and myths which, as in the case of other beverages, ${ }^{2}$ have precarious scientific foundations, if any.

One of the more indisputable popular statements on crema claims that "any error in grinding or in percolation, in temperature or extraction level, is immediately denounced by the color, the texture and the persistence of the foam". This statement is supported by almost a century of "trial and error" rather than objective and reproducible characterizations. It is worth mentioning that the espresso brewing method and equipment were only technically described almost 70 years after its invention and data on 
physicochemical and structural aspects have been reported only in the last 20 years by Italian scientists. ${ }^{3,4}$

The aim of the present work is to organize and to structure the knowledge so far achieved on espresso coffee foam, from a scientific point of view. The reported experimental data on the physical properties of the espresso coffee foam will be discussed in view of brewing process/ chemistry interplay.

\section{What is Espresso Coffee Foam}

A foam is a coarse dispersion of gas bubbles in a liquid continuous phase. In the case of espresso coffee, the gas phase is mainly the carbon dioxide generated during coffee roasting and entrapped within the cell structure, whereas the continuous phase is an oil in water $(\mathrm{O} / \mathrm{W})$ emulsion of microscopic oil droplets $(90 \%<10 \mu \mathrm{m})$ in an aqueous solution of several solutes (including sugars, acids, proteinlike material, and caffeine) containing solids coffee cellwall fragments of $2-5 \mu \mathrm{m} .{ }^{1}$ The typical pure Coffea arabica regular $(30 \mathrm{~mL}$ cup volume percolated in $30 \mathrm{~s}$ ) espresso liquid is an $\mathrm{O} / \mathrm{W}$ emulsion of $0.2-0.3 \%$ volume fraction, a suspension in which the dispersed phase is represented by about $150 \mathrm{mg}$ solid coffee particles (corresponding to about $5 \mathrm{~g} / \mathrm{L}$ ) and a solution with total soluble solids concentration of $52.5 \mathrm{~g} / \mathrm{L}{ }^{1}$

According to Dickinson, ${ }^{5}$ the espresso coffee foam (herein called crema for the sake of brevity) can be classified as a metastable foam with a specific lifetime. This is the time at which the foam disappears so as to expose the dark surface of the beverage below, which can be up to $40 \mathrm{~min}^{3}$ During the short lifetime of crema, its structure and properties change considerably. It starts as a liquid bubbly foam in freshly prepared espresso and becomes a dry polyhedral foam on aging. The latter, however, is not of practical interest from a consumer point of view, since espresso coffee is consumed within a few minutes after preparation.

From a quantitative point of view, the crema should represent at least the $10 \%$ of the volume of an espresso. ${ }^{1}$ Foam density, as a gross indication of the gas phase content, in the range $0.40-0.60 \mathrm{~g} / \mathrm{mL}$ has been reported. ${ }^{6}$ No detailed study has been published so far on crema chemical composition as well as on bubble size distribution. For the latter, the technical literature describes pure Coffea canephora (known as robusta) crema having larger bubbles than that of coffee made from pure C. arabica. ${ }^{7}$ An essentially monomodal distribution ranging from 10 to $150 \mu \mathrm{m}$ has been reported for a regular pure C. arabica espresso. $^{8}$

It has been reported that taste-wise, crema is of little sensory interest, ${ }^{4}$ although, if tasted in the absence of beverage, some bitterness and astringency can be clearly perceived.

\section{Traditional Espresso Preparation Method}

Although traditional espresso coffee preparation is a very complex and challenging topic to which several detailed reviews have been dedicated, ${ }^{1,7,9}$ it is possible to simplify the process to the following three key events to describe the whole set of steps involved:

- Grinding of the roasted coffee

- Coffee powder dosing and tamping

- Brewing (more correctly Percolation)

Preliminary blending and roasting are taken for granted, and will be discussed later. It has to be stressed out that the brewing has to be performed at the moment, on demand. This concept is clarified by the saying "the consumer, not the espresso must wait!".

Grinding The objective of grinding is to obtain a distribution of particles suitable to offer the proper fluiddynamics. ${ }^{10}$ An appropriate particle size distribution can be modeled either by a power-law or log-normal distribution, occasionally with a typical bimodality or even trimodality. Such a complex characteristic of particle size is believed to produce a double effect: it forms a coarse fixed structure, which allows the correct flow through the cake and it forms large quantity of fines of high specific surface, which permit the extraction of large amount of soluble and emulsifiable material. ${ }^{1}$ The particle size range is $0.2-650 \mu \mathrm{m}^{11}$

Grinding destroys the roasted coffee cell structure and this results in a remarkable release of carbon dioxide, with obvious consequences on crema, albeit not yet studied in detail. Barbera ${ }^{12}$ demonstrated that over $70 \%$ of the carbon dioxide was released following coffee grinding into 500$\mu \mathrm{m}$ particles. It has to be mentioned that even in the absence of grinding, carbon dioxide is released from roasted coffee beans and this degassing process has been investigated since it represents a technological issue for coffee packaging and shelf life. ${ }^{13,14}$ Since it is not possible to carry out the coffee extraction without coffee grinding, to limit the detrimental effect of the carbon dioxide loss on crema it is necessary to be quick in preparing espresso immediately after grinding. It has been reported that the range $0-30 \mathrm{~min}$ is the interval between grinding and espresso preparation, and should not be exceeded so as to preserve crema quality. ${ }^{15}$

Dosing and Tamping The coffee portion, e.g., the weight of roasted and ground coffee required for preparing one cup, is 
normally confined in the range $6.0-8.0 \mathrm{~g}^{1}$ but the upper limit can reach 9.0 g. ${ }^{16}$ The quantity of coffee powder and the tamping are the two factors which affect coffee cake porosity. The latter, is the coffee bed property which governs the water/coffee contact time and then both the extraction yield and the foam quality. The compacting force may vary from a few kilograms, for a vertical upward thrust (a tamping plate is usually built-in with the grinder), to approximately $20 \mathrm{kgf}$ for a downward compacting by a hand tool. ${ }^{1}$

Brewing Traditional espresso requires specialized equipment that can heat water to a temperature of $92-94{ }^{\circ} \mathrm{C}$ and then pressurize it to $9 \pm 2$ bar. $^{11}$ The portion is placed in a perforated basket (also known as a filter) and compacted. Once the proper porous medium is created it is possible to start the percolation of hot water under pressure through the coffee bed. It has to be stressed that the energy of the water pressure is spent within the coffee cake. ${ }^{1}$ The beverage flow into the cup should be ideally close to $1 \mathrm{~mL} / \mathrm{s}^{11}$ but the range $0.40-2.73 \mathrm{~mL} / \mathrm{s}$ has been recently reported in a survey of barista habits in Italian coffee shops. ${ }^{16}$ The process is applied (percolation time) until the beverage volume in the cup meets the personal preferences of the consumer and/or the regional traditions, in Italy for instance inside the range $15-50 \mathrm{~mL}$, with an optimal outcome at 25 $30 \mathrm{~mL}$ (regular espresso). The whole set of factors controlling the percolation is very crucial for the color of the foam: if the latter is pale, it means that the espresso has been "under extracted", probably because of too coarse grind, too low water temperature or too short time. If the crema is very dark in hue and has a white spot in the middle, it is likely that the consistency of the coffee grounds was too fine or the quantity of grounds was too large. An "over extracted" espresso exhibits either a white foam with large bubbles if the water was too hot or just a white spot in the center of the cup if brewing time was too long. ${ }^{11}$

Foam color can also reveal the composition of the coffee blend: a pure $C$. arabica blend leads to an espresso foam characterized by a reddish-brown color with a "tiger skin" or "tiger tail" pattern not presented by a pure C. canephora crema which is characterized by a dark brown color with grey tones. ${ }^{7,17}$ These two species are those commercially used among the over 60 Coffea species (a genus belonging to the Rubiaceae family). Differences between arabica and robusta coffee are generally very pronounced and well documented. ${ }^{1}$ The aroma profiles as well as the chemical composition of arabica and robusta coffee brews are different. Total lipids (about twice as high in arabica as in robusta brews) and caffeine content (about twice as high in robusta as in arabica brews) are the main differences between the two types of brew. Because of its superior quality and taste, arabica sells for a higher price than its harsher, rougher "relative". ${ }^{11}$

It has been claimed that the use of robusta is indispensable to confer a proper crema to an Italian espresso $^{3}$ however this claim has been substantially contradicted by recent experimental data, as discussed in the following. In Figure 1, the "tiger skin" pattern is shown.

Roasting and Carbon Dioxide The origin of the gas phase in the espresso coffee foam resides in the roasting process. Coffee beans are roasted using hot combustion gases or air at temperatures above $200{ }^{\circ} \mathrm{C}$ to develop the characteristic flavor, color, and aroma. ${ }^{18}$ Carbon dioxide is the major gas produced during roasting $(87 \%$ of gases released from roasted coffee together with $7.3 \%$ of carbon monoxide), formed as a result of the many reactions occurring, among which Strecker degradation: a secondary step in the Maillard reactions and pyrolysis of carbohydrates. Roasting degree can be expressed in terms of total weight loss (moisture+organic compounds) or organic loss (organic compounds only, as $\%$ dry matter). For what concern the latter: $1-5$ corresponds to light; $5-8$ to medium, $8-12$ to dark; $>12$ to very dark roasting degree. In a recent paper, the initial carbon dioxide content, measured immediately after grinding, has been found to range from 4.0 to $8.6 \mathrm{mg} /$ $\mathrm{g}$ of coffee, with an overall average of $5.7 \mathrm{mg} / \mathrm{g}(2.9 \mathrm{~mL} / \mathrm{g}$ at Standard Temperature and Pressure, STP). ${ }^{19}$ The pure arabica sample analyzed by those authors was characterized by a lower carbon dioxide content (average $4.6 \mathrm{mg} / \mathrm{g}$ coffee) than that of the pure robusta one $(6.9 \mathrm{mg} / \mathrm{g}$ coffee). Both coffee samples contained more carbon dioxide in a dark roast rather than at a medium roast. ${ }^{19}$

It has also been reported that two additional reactions that occur in the espresso brewing method can be indicated as a source of carbon dioxide. Both derive from bicarbonate ions contained in the water: the second most important ingredient to brew coffee. In particular, carbon dioxide

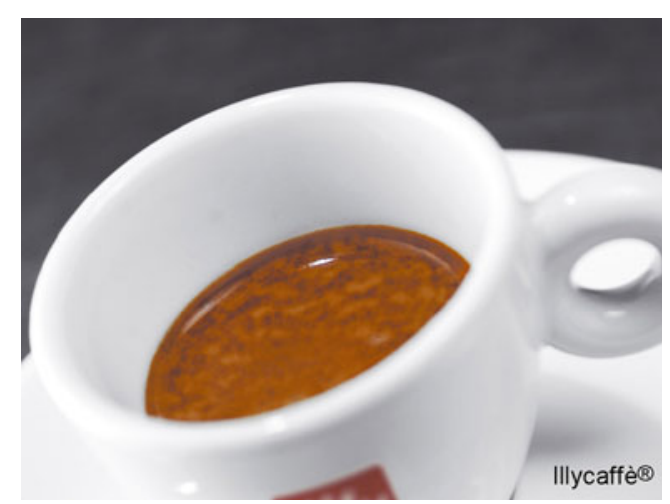

Fig. 1 Image of freshly prepared pure arabica regular espresso coffee foam. The "tiger skin" effect is shown 
from bicarbonate thermal decomposition and from bicarbonate neutralization by natural coffee acids. ${ }^{20-22}$

During percolation, the beverage should be conveyed into a proper cup. As in the case of beer, both pouring style and cup characteristics are very important factors which may affect the crema. In particular, the cup shape and material, the distance between cup and beverage conveyor and the temperature of the empty cup are particularly relevant. For the latter, it is well known that an excellent espresso is always prepared in a warm cup. ${ }^{1,7}$

\section{Surfactants and Foam Stability}

It is well known that for food foams and emulsions the preparation, properties, and long-term stability are determined by the adsorption and subsequent interactions between various molecular species at air-water and oilwater interfaces. In real food systems, the interfaces will be populated by a large number of molecular species, which may include various proteins, surfactants, lipids, and polysaccharides.

The chemical nature of coffee surfactants has not yet been fully clarified. In the first chemical characterization of a pure arabica blend espresso coffee brew (both whole and fractionated) some classes of surfactant have been quantitatively determined, albeit not recognized as surfactants at that time. ${ }^{4}$ In particular, proteins and lipids have been analyzed the latter in terms of triacylglycerides, diacylglycerides, and fatty acids, showing that the first five fractions (about $5 \mathrm{~mL}$ each) corresponding cumulatively to a regular espresso cup volume contained about $2.1 \mathrm{mg} / \mathrm{mL}$ triacylglycerides, $0.4 \mathrm{mg} / \mathrm{mL}$ diacylglycerides, and $0.09 \mathrm{mg} / \mathrm{mL}$ fatty acids. The same investigation reported whole beverage total lipids concentration of $1.80 \mathrm{mg} / \mathrm{mL}$ and of $0.55 \mathrm{mg} /$ $\mathrm{mL}$ in espresso for pure arabica (from a sample different from that used for fractionation) and for pure robusta blend, respectively. ${ }^{4}$

It has been also suggested that other classes of complex molecules, like glycolipids or glycoproteins might be involved in the formation and/or stabilization of the foam. ${ }^{1}$

Nunes et al..$^{23}$ determined foamability and foam stability of espresso coffee as a function of the roasting degree along with other dependent variables like total solids, $\mathrm{pH}$, fat, protein, and carbohydrate contents. They observed a high correlation between foamability and protein content, and between foam stability and the fractions containing highmolecular-weight polysaccharides; these fractions are a mixture of galactomannan and arabiinogalactan or better, complexes between polysaccharides, protein, and phenolic compounds caused by the roasting process, probably products of Maillard reactions. ${ }^{24}$ The same investigation put in evidence the strong negative correlation between fat and foamability. ${ }^{23}$

The first foaming fraction isolated from ground and roasted coffee has been obtained by Navarini et al. ${ }^{25}$ and characterized by the same group. ${ }^{26,27}$ Addition of ammonium sulphate to the coffee extract (defatted dark roast arabica blend extracted by solid-liquid extraction with water at $90{ }^{\circ} \mathrm{C}$ ) produced a precipitate which was redissolved, dialyzed and freeze-dried. This fraction, also known as Total Foaming Fraction (TFF) when redissolved in water, easily foams on shaking. By using the same procedure on different arabica and robusta pure single origin coffee samples, yield, chemical and physicochemical properties resulted to be independent from coffee species and origin. ${ }^{27}$ TFF was further fractionated by means of isopropanol precipitation to get foaming fraction A (FFA) and $\mathrm{B}$ (FFB). The former was found to be composed of about $80 \%$ (on molar basis) of mannan, containing small amounts of galactose and arabinose, and of about $20 \%$ of arabinogalactan. ${ }^{25}$ FFA, characterized by high molecular weight $(34,000-47,000)$ and moderately low surface activity, was shown to be involved in foam stability whereas FFB, melanoidin-proteinaceous material, with lower molecular weight $(8,500-17,000)$ and high surface activity was shown to be involved in foamability. ${ }^{27}$ TFF, FFA, and FFB dissolved in water at $0.4 \% w / v$ gave an average surface tension (De Nouy tensiometer at $25^{\circ} \mathrm{C}$ ) of $51.9,59.5$, and $46.5 \mathrm{mN} / \mathrm{m}$, respectively. ${ }^{27}$

Very recently TFF, FFA, and FFB have been isolated from an arabica $(30 \%) /$ robusta $(70 \%)$ blend and their foaming performances and viscoelastic properties have been determined. ${ }^{28}$ The whole set of experimental data substantially confirmed previous findings. The interfacial elasticity of $0.5 \% \mathrm{FFB}$ in water plotted as a function of time, described the typical behavior obtained for proteinlike biopolymers ${ }^{28}$ characterized by values in the range typical of food-stabilizing proteins. ${ }^{29}$

The role played by soluble proteins in promoting and by coffee oil in inhibiting coffee foam volume and foam stability has been also reported by Saliba and Ayoub. ${ }^{30}$

In order to avoid possible influence of the extraction conditions on coffee foam positive compounds, D'Agostina et al. ${ }^{31}$ isolated TFF, FFA, and FFB directly from a defatted espresso obtained under strictly controlled brewing conditions using a pure arabica coffee blend. Chemical composition and physicochemical properties were found to be in reasonable agreement with findings of Navarini and Petracco $^{26}$ and Petracco et al. $^{27}$ The three foaming fractions have been also organoleptically tested. FFA has been found to be essentially tasteless whereas all panelists agreed that FFB has an intense coffee aroma and persistent bitter taste. ${ }^{31}$ Due to the higher foam promoting activity of FFB, this fraction was further subfractionated by means of 
solid phase extraction on $\mathrm{C} 18$ cartridges and subsequent elution with different water/methanol mixtures. Four subfractions (FFB-1-FFB-4) were obtained but only the first two, more hydrophilic, were characterized. FFB-1 showed no foamability, whereas FFB-2, slightly more hydrophobic (elution with $50 \%$ methanol), was very effective both in foam formation and stabilization. As far as chemical composition is concerned, FFB-2 was found to be essentially a melanoidin having cinnamic derivatives as well as polysaccharides and modified proteins structural elements characterized by a monomodal molecular weight distribution centered at $56,000 .^{31}$

Caffeine shows appreciable surface activity in water which is enhanced by the presence of sucrose, ${ }^{32}$ however, in view of the entity of the adsorption phenomenon (for $1.0 \%$ pure caffeine at $20{ }^{\circ} \mathrm{C}$ monitored up to $20 \mathrm{~h}$, it showed a surface tension equal to 70.1 and $68.5 \mathrm{mN} / \mathrm{m}$ in mixture with $6.0 \%$ sucrose) it seems difficult to attribute a relevant role of caffeine content as a surfactant. ${ }^{33}$

\section{Espresso Coffee Interfacial Properties}

\section{Air-Beverage Interface}

In spite of the crucial role played by interfacial properties in foaming, reported data on espresso coffee have been confined to surface tension measurements carried out by means of stalagmometry. ${ }^{17,34-37}$ Unfortunately, besides indicating the presence of naturally occurring surfactants in the beverage, this method cannot provide information about their kinetics of adsorption. Reported surface tension values at $20{ }^{\circ} \mathrm{C}$ for pure arabica espresso range from 46 to $49.7 \mathrm{mN} / \mathrm{m}$ whereas for pure robusta or robusta-rich blends slightly higher values have been reported $(48-50.5 \mathrm{mN} / \mathrm{m})$.

Recently, dynamic tensiometry has been used to compare regular espresso coffee prepared by using pure arabica (Brazil) and pure robusta (Congo). By using both maximum bubble pressure and drop shape tensiometry it has been possible to follow adsorption kinetics in a wide range of surface age ranging from $10^{-3} \mathrm{~s}$ to hours. ${ }^{38} \mathrm{~A}$ strong reduction of surface tension was observed already at short time, suggesting that in addition to high-molecular-weight surfactants, low-molecular-weight amphipathic solutes are involved. The comparison between the two different Coffea species at $20{ }^{\circ} \mathrm{C}$, revealed a similar behavior in the time range from $10^{-3}$ to $10 \mathrm{~s}$ with surface tension values at about $4 \mathrm{~s}$ close to those obtained by stalagmometry (46.2 and $48.7 \mathrm{mN} / \mathrm{m}$ for arabica and robusta, respectively). However, for both species the surface tension tended to reach an equilibrium value at time higher than $900 \mathrm{~s}$ this behavior being particularly remarkable at $37{ }^{\circ} \mathrm{C}$ and especially for arabica espresso. In other words, the robusta sample tended to a steady state more rapidly that the arabica one. The different behavior has been ascribed to the lipids content in the brews. In particular lipids form insoluble monolayers at the interface reaching equilibrium with a slow adsorption process. ${ }^{39}$

This hypothesis has been indirectly confirmed by studying the dynamic tensiometric behavior of several coffee-based beverages and pure arabica espresso at different cup (serving) volumes which differed in lipid content. $^{40}$

Surface tension (at $10 \mathrm{~s}$ ) has been found to be influenced by the cup (serving) volume (percolation time) and in particular by increasing the cup volume from 10 to $60 \mathrm{~mL}$. The surface tension increased from $44 \mathrm{mN} / \mathrm{m}$ to about $48 \mathrm{mN} / \mathrm{m}$ following a power law with an exponent close to $0.042 .^{41}$

Considering that the first sip of espresso coffee is generally consumed at high temperature (ca. $60-65{ }^{\circ} \mathrm{C}$ and accordingly surface tension values lower than those measured at $37^{\circ} \mathrm{C}$ ) the dynamic tensiometric behavior of the espresso coffee beverage has been suggested to be consistent with that expected for systems with good wetting properties of the oral cavity. ${ }^{41}$ As a matter of fact it has to be mentioned that human whole saliva at $37{ }^{\circ} \mathrm{C}$ is characterized by surface tension values remarkably higher than those of regular espresso beverage at the same temperature. Moreover, the critical surface tension of wetting representative of a human saliva-coated tooth surface and most restorative materials when exposed in the oral cavity has been reported to be close to $35-38 \mathrm{mN} /$ $\mathrm{m}^{42}$ and within the bio-adhesive range of $32-50 \mathrm{mN} / \mathrm{m}^{43}$

In addition to surface pressure, the dilational modulus of the interfacial adsorption layer plays an important role in the surface properties. It has been stated that the dilational modulus of a generic "coffee" is rather high and may explain in part the stability of bubbles. However, no data have been reported to support this claim. ${ }^{33}$

\section{Solid-Beverage Interface}

Up to now, surface properties of espresso coffee have been investigated on Teflon surfaces only ${ }^{40}$ with the purpose to provide further evidence confirming the hypothesized good wetting properties for the oral cavity. Wetting of espresso coffee on a hydrophobic surface is higher than that of popular drip filter coffee preparations. The reported data show that the increase in temperature from 20 to $45{ }^{\circ} \mathrm{C}$ promotes the spreading by reducing the contact angle and the surface tension. In particular going from an initial contact angle at $20{ }^{\circ} \mathrm{C}$ of about $60^{\circ}$ to an initial contact angle close to $40^{\circ}$ at $45^{\circ} \mathrm{C}$.

In Figure 2, pure water (contact angle $97^{\circ} \pm 1^{\circ}$, upper left), human whole stimulated saliva (upper right), drip 


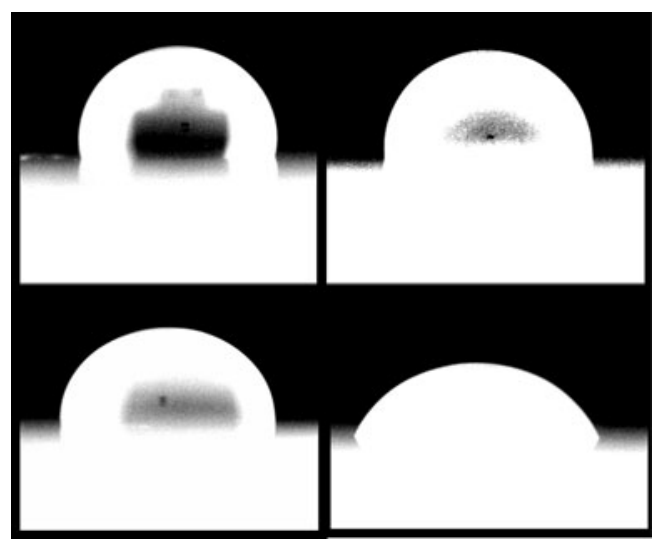

Fig. 2 Pure water (contact angle $97^{\circ} \pm 1^{\circ}$, upper left), human whole stimulated saliva (upper right), drip coffee (bottom left), and espresso (bottom right) are compared on the Teflon surface used by Ferrari et al. ${ }^{40}$

coffee (bottom left), and espresso (bottom right) are compared on the Teflon surface used by Ferrari et al. ${ }^{40}$

The remarkable wettability of espresso coffee may be of interest to interpret some peculiarities like the staining ability of the beverage for the oral cavity surfaces and its long-lasting after-taste. It is well known that taste and aroma of espresso can be savored for as long as $20 \mathrm{~min}$ after it has been drunk. ${ }^{11}$

Human enamel and mucosal surfaces are very important components of the oral cavity. Contact angles of water and human whole saliva measured on enamel in vitro at $37{ }^{\circ} \mathrm{C}$ show a better wettability of water (values close to $50^{\circ}$ ) than whole saliva (values close to $65^{\circ}$ ). Very different is the behavior of the two liquids on mucosal surface (in vivo measurements at room temperature), being the contact angle of water $\left(75^{\circ}-70^{\circ}\right)$ significantly higher than that of human whole saliva (close to $65^{\circ}$ ). ${ }^{44}$ It has been reported that some coffee components adsorb onto saliva-coated hydroxyapatite beads inhibiting the adsorption of Streptococcus mutans which is considered to be the major causative agent of dental caries in humans. ${ }^{45}$ It is clear that the ability to adhere to the tooth surface by binding water insoluble polysaccharides and saliva constituents of the acquired pellicle may reflect specific interactions occurring in addition to surface properties (wetting and spreading).

The contact angles of a bitter taste system $(1 \% \mathrm{w} / \mathrm{v}$ caffeine aqueous solution) and a sweet taste system $(6 \% \mathrm{w} /$ $v$ sucrose aqueous solution) have been measured at $20{ }^{\circ} \mathrm{C}$ on a hydrophobic surface (polyethylene) to mimic the receptor membrane-tastant interaction. According to the authors, the lower value found for caffeine of $85^{\circ} \pm 0.75^{\circ}$ versus $91^{\circ} \pm 0.95^{\circ}$ for sucrose, suggests there is specific adsorption of the bitter caffeine molecules on the lipidic bilayer surface of receptor membrane. ${ }^{32}$

As in the case of surface tension, the above reported data shows a very low contribution of caffeine in wetting of espresso coffee.

\section{Solid-Foam Interface}

No investigations on solid-espresso foam interfacial properties have been reported so far, although recently, Foschia ${ }^{46}$ observed a foam adhesion phenomenon similar to that known as foam lacing or cling in beer. ${ }^{47}$ When beer is poured, changes occur in the foam which convert it from being liquid to being essentially solid, which leads to the foam being left in contact with the glass surface when liquid is drained. Those beers most prone to this change give the most adhesive foam. It is interesting to underline that beer foam is equally able to lace onto virtually any type of solid surface indicating that there is no role for specific types of foam-glass interactions in beer foam lacing. ${ }^{47}$ Unhopped beer is not able to give rise to foam adhesion; low-molecular-weight species (iso-alpha-acids) in hopped beers and their interactions with foam positive proteins have been suggested to reinforce and stiffen bubble films and then to give cling. ${ }^{48}$ More recently, free fatty acids and in particular di- and trihydroxyoctadecenoic acids have been shown to negatively affect beer foam adhesion. $^{49}$

Foschia, ${ }^{46}$ in a study on espresso coffee foam, observed foam adhesion, independently of solid type (borosilicate glass, polystyrene, polyethylene, and Teflon), for espresso prepared with pure robusta (two single origins). Foam adhesion has not been observed in the case of pure arabica espresso (five single origins). The foam adhesion observed in the case of pure robusta has been related to the observed higher drainage rate and consequently, to the faster change from a liquid foam to a dry one. ${ }^{46}$

A further difference between the foam obtained by pure arabica espresso and that of pure robusta is the special visual pattern known as "tiger skin" or "tiger tail" not observed in the latter. This effect is attributed to the presence in the foam of very fine coffee grounds along with cell-wall fragments and it may reflect the different cellular structure between the two coffee species and then as well as the different behavior when subjected to grinding. ${ }^{50}$ The presence of a high fraction of solid particles in pure arabica crema may be the origin of the differences evidenced in Figure 3. However in addition to the visual aspect, the solid particles in the arabica crema may be considered an additional class of surfactants which can play a role in the foam stabilization. ${ }^{51}$

No detailed studies have been focussed at determining the role played by solid particles in crema. Optical microscopy was used in a preliminary observation. ${ }^{52}$ In Figure 4 (pure arabica regular espresso freshly prepared), a large bubble appears to be covered by solid particles (size $<50 \mu \mathrm{m})$. The particle surface seems to mostly remain on the external side suggesting a contact angle (through the aqueous phase) of less than $90^{\circ} .{ }^{51}$ 

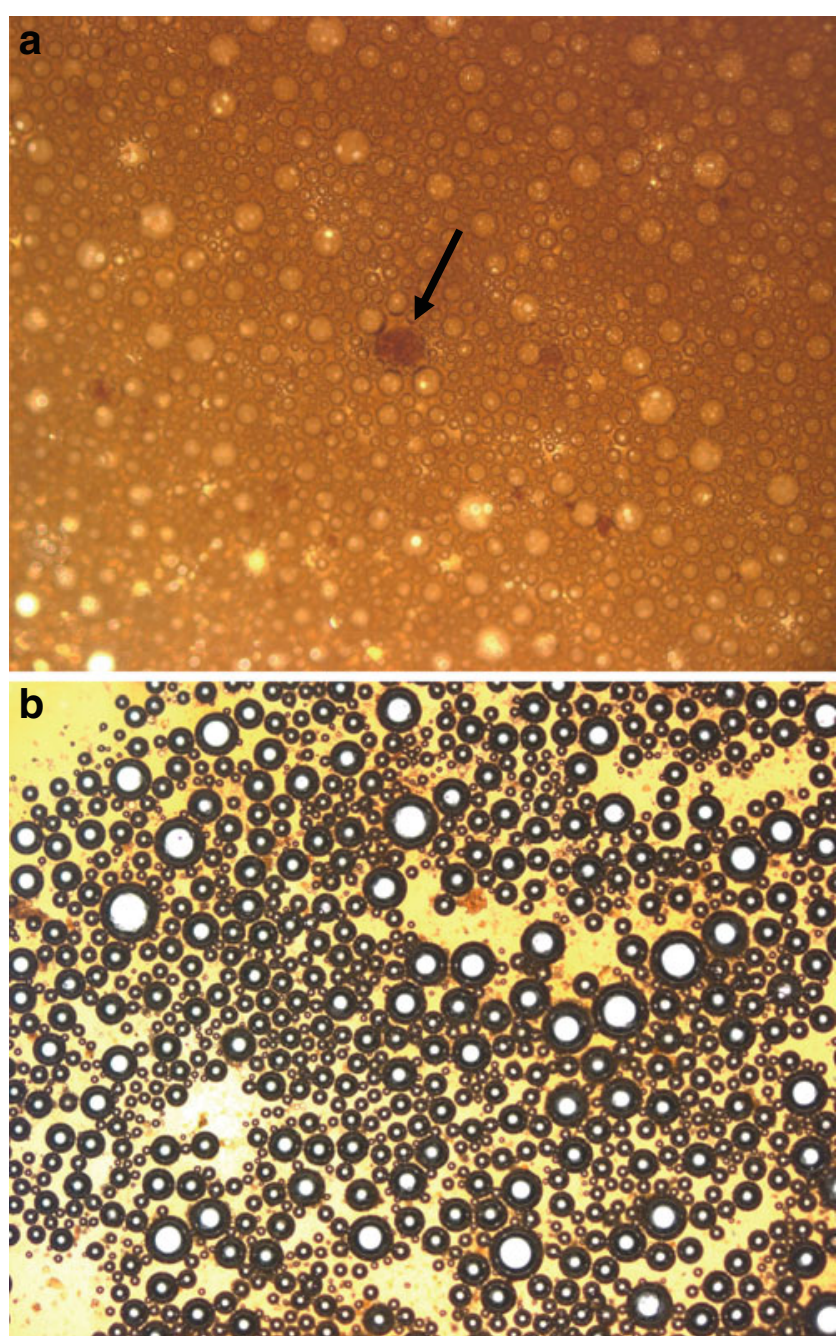

Fig. 3 Optical microscopy image of a freshly prepared pure arabica regular espresso coffee foam pattern b freshly prepared pure robusta regular espresso coffee foam pattern. The arrow shows a solid particle of $120 \mu \mathrm{m}$ as a size reference, Silizio $^{52}$

The particles in the dry espresso foam shown in Figure 5 (pure arabica), are clearly located in the Plateau border, suggesting the tendency to be unattached. In fact, during drainage, unattached particles predominantly follow the net motion of the liquid. ${ }^{53}$ This observation strongly suggest possible stabilizing role of the solid particles within the crema.

\section{Espresso Coffee Foam Properties}

It has to be emphasized that the methods used to determine the physical properties of espresso coffee foam are empirical and have not yet been standardized, therefore, for the sake of clarity, both methods and samples, when mentioned, are briefly described in what follows.

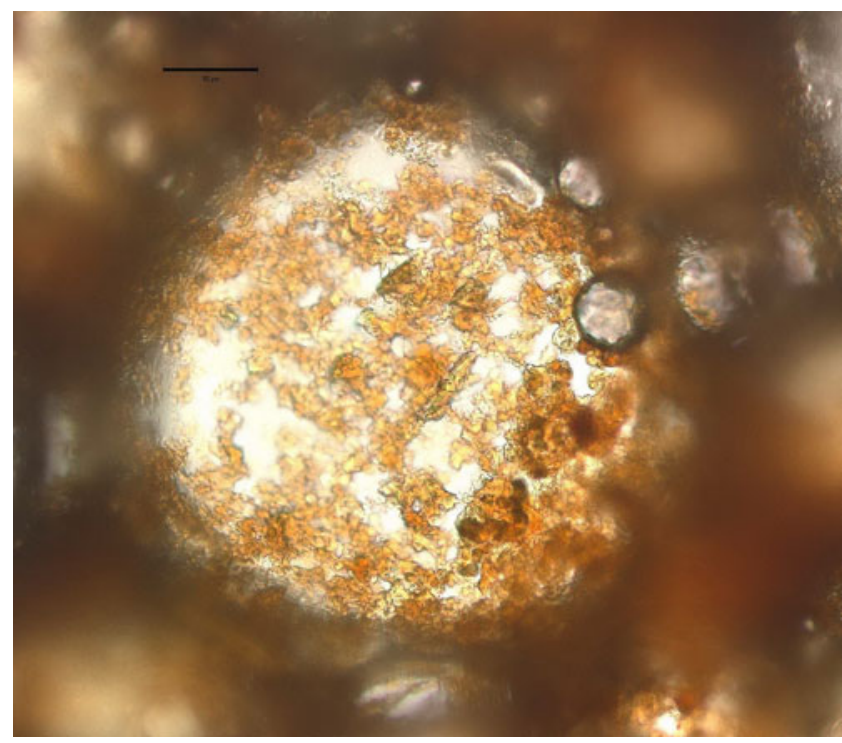

Fig. 4 Optical microscopy image of a large bubble isolated from a freshly prepared pure arabica regular espresso coffee foam. The scale bar represents $50 \mu \mathrm{m}$. Silizio ${ }^{52}$

\section{Foam Volume}

Earlier studies ${ }^{3}$ on espresso coffee prepared by using arabica/robusta (40:60) blend reported the foam volume, measured in a graduated beaker immediately after percolation, as a function of water content of the ground roasted coffee, of compaction in the filter holder and of coffee portion. Unfortunately, the roasting degree was not specified. The foam volume range is shown in Table 1 . According to reported data, ${ }^{3}$ a low water content $(2.2 \%)$ of the ground roasted coffee, high compaction force $(10 \mathrm{~kg})$ and a 6.5 -g portion led to the higher foam volume. The detrimental effects of poor compaction as well as of

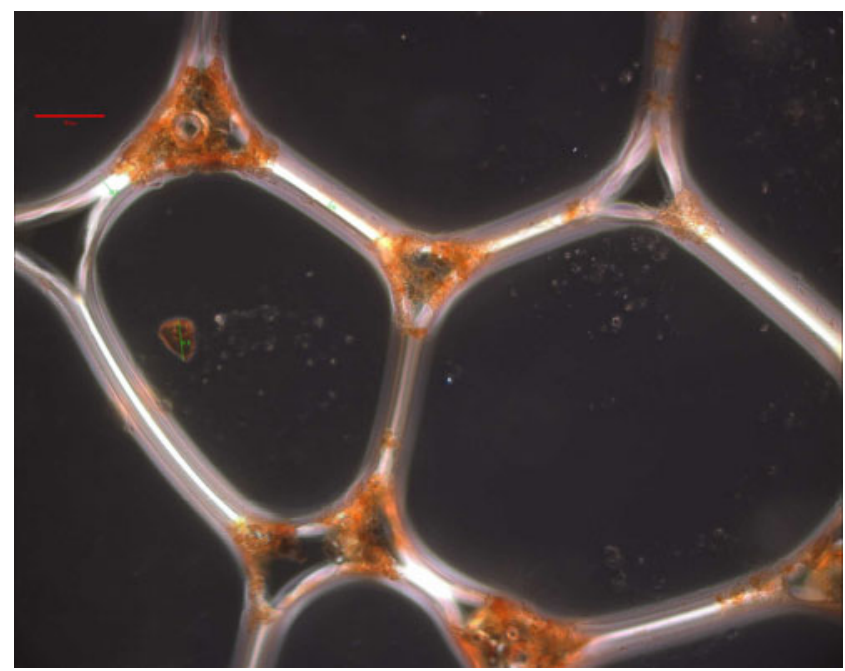

Fig. 5 Optical microscopy image of a dry pure arabica regular espresso coffee foam. The scale bar represents $50 \mu \mathrm{m}$. Silizio ${ }^{52}$ 
Table 1 Espresso coffee foam volume reviewed data

\begin{tabular}{|c|c|c|c|c|c|c|}
\hline $\begin{array}{l}\text { Blend } \\
A=\text { arabica } \\
R=\text { robusta }\end{array}$ & $\begin{array}{l}\text { Coffee portion }(\mathrm{g}) / \text { cup volume } \\
(\mathrm{mL})\end{array}$ & $\begin{array}{l}\text { Roasting } \\
\text { degree }^{\mathrm{a}}\end{array}$ & Water temperature $\left({ }^{\circ} \mathrm{C}\right)$ & $\begin{array}{l}\text { Water pressure } \\
\text { (bar) }\end{array}$ & $\begin{array}{l}\text { Foam volume } \\
(\mathrm{mL})\end{array}$ & Reference \\
\hline $\mathrm{A} / \mathrm{R}$ 40:60 & $5.0-7.5 / 40$ & NR & NR & NR & $3.5-10.0$ & 3 \\
\hline A & $6.75 / 30$ & Medium & $93 \pm 1$ & $9 \pm 2$ & At least 2.7 & 34 \\
\hline A & $6.0 / 40$ & Light-very dark & NR & NR & $1.2-3.5$ & 23 \\
\hline $\mathrm{R}$ & $6.0 / 40$ & Light-very dark & NR & NR & $1.4-3.9$ & 23 \\
\hline A & $7.5 / 40$ & NR & 96 & 9 & 4.4 & 17 \\
\hline $\mathrm{A} / \mathrm{R} 20: 80$ & $7.5 / 40$ & NR & 96 & 9 & 6.8 & 17 \\
\hline A & $7.5 / 40$ & NR & 92 & $7-11$ & $5.1-6.9$ & 35 \\
\hline A & $7.5 / 40$ & NR & $88-98$ & 9 & $4.3-4.5$ & 36 \\
\hline $\mathrm{A} / \mathrm{R} 20: 80$ & $7.5 / 40$ & NR & $88-98$ & 9 & $5.9-6.9$ & 36 \\
\hline A & $6.5-8.5 / 40$ & NR & 92 & 9 & $4.4-6.0$ & 37 \\
\hline $\mathrm{A} / \mathrm{R} 20: 80$ & $6.5-8.5 / 40$ & NR & 92 & 9 & $5.5-9.42$ & 37 \\
\hline A & $6.75 / 4-20$ & Medium & $93 \pm 1$ & 9 & $1.37-4.5$ & 46 \\
\hline A & $6.75 / 25$ & Medium & $93 \pm 1$ & 9 & $2.5-12$ & 6 \\
\hline
\end{tabular}

$N R$ not reported

${ }^{\mathrm{a}}$ See text for definition

prolonged time between grinding and extraction were emphasized.

In particular, holding for $24 \mathrm{~h}$ at equilibrium with ambient conditions led to a remarkable decrease of the foam volume (from 10 to $6.5 \mathrm{~mL}$ ).

Illy and Viani ${ }^{34}$ defined as "foam index" the ratio between foam and liquid volumes. A "foam index" of at least $10 \%$ is expected for a correct preparation.

Nunes et al. ${ }^{23}$ stimulated by the findings of Dalla Rosa et al. ${ }^{3}$ reported a more detailed study. Pure arabica (Brazil) and robusta (Uganda) were roasted to different roasting degree (from light to very dark), degassed for 2 days at room temperature and then espresso coffee was prepared from these species and analyzed. The foam volume, was measured immediately after extraction using a $50 \mathrm{~mL}$ graduated cylinder and ranged from 1.2 to $3.9 \mathrm{~mL}$, as shown in Figure 6.

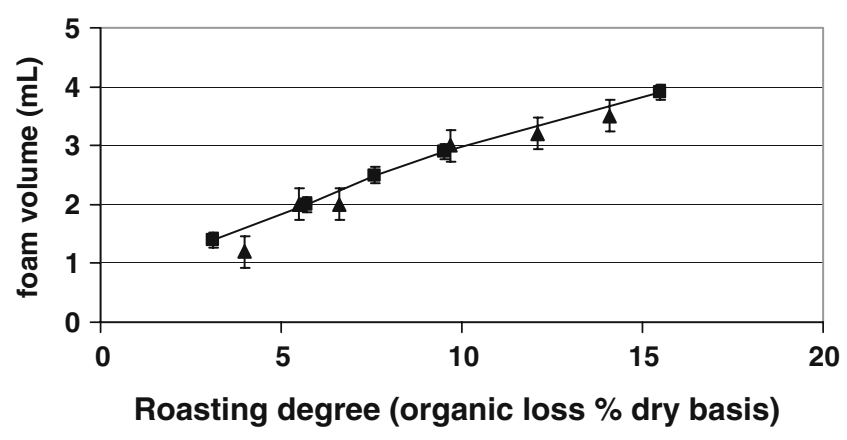

Fig. 6 Foam volume (in milligrams) as a function of roasting degree (organic loss $\%$ dry basis) after Nunes et al. ${ }^{23}$ Triangle pure Arabica; square pure Robusta
This range includes values lower than those measured by Dalla Rosa et $\mathrm{al}^{3}{ }^{3}$ and lower than those expected for wellprepared cups (of identical volume) ${ }^{34}$ the roasting, however, had been performed at a temperature $\left(200{ }^{\circ} \mathrm{C}\right)$ lower than that normally used to roast coffee blend for espresso brewing. The roasting temperature remarkably affects the carbon dioxide coffee content, in particular roasting at $200{ }^{\circ} \mathrm{C}$ produces about $3 \mathrm{~mL} \mathrm{CO} / \mathrm{g}$ coffee STP while roasting at $230{ }^{\circ} \mathrm{C}$ produces about $9 \mathrm{~mL} \mathrm{CO} / \mathrm{g}$ coffee STP. ${ }^{12}$ As seen in Figure 6, the foam volume was found to increase linearly with roasting degree for both coffee species. No significant differences in the foam volume were observed in comparing arabica and robusta (see Figure 6). The water content of the roasted coffee was not found to affect the foam volume, as previously reported. ${ }^{3}$ A good correlation between beverage $\mathrm{pH}$ and foam volume has been also observed. ${ }^{23}$ Maetzu et al. ${ }^{17}$ compared the foam volume (measured in a $100-\mathrm{mL}$ graduated cylinder) of espresso prepared by using pure arabica (Colombia) and arabicalrobusta (20:80) blend without details on roasting degree. The reported values (see Table 1) proved the higher foamability of the blend. The foam volume was found to be affected by water pressure. ${ }^{35}$ As reported in Table 1, by increasing water pressure, the foam volume steadily increases from 5.1 to $6.9 \mathrm{~mL}$. The water temperature in the range $88-98{ }^{\circ} \mathrm{C}$ was not statistically different as far as the foam volume is concerned, whereas the coffee portion strongly influenced foam volume which steadily increased. ${ }^{36,37,54}$

Unfortunately, in the above-mentioned investigations, no details on water quality as well as on roasting degree have 
been provided and carbon dioxide content has not been determined.

By using back-scatter technique, ${ }^{55}$ Foschia ${ }^{46}$ investigated foam volume as a function of percolation time (cup volume) ranging from a few drops (e.g., $4 \mathrm{~mL}$ ) to $20 \mathrm{~mL}$ espresso. In this interval, the foam volume ranges from 1.37 to $4.5 \mathrm{~mL}$ showing an almost linear trend. In the same study, the linear correlation between foam volume and roasting degree has been confirmed but not over the whole range of roasting degree: a very dark roast coffee produced less foam than that of a dark one. ${ }^{46}$

Two different methods to quantitatively determine the espresso foam have been compared by Navarini et al.. ${ }^{6}$ In addition to the graduated cylinder $(100 \mathrm{~mL})$ method, the espresso has been percolated into a $100-\mathrm{mL}$ separatory funnel and the crema determined gravimetrically (foam weight) after the liquid was drained off. For the first time, foam volume has been investigated as a function of the carbon dioxide content of roast coffee. Foam volume and foam weight was shown to be highly correlated to carbon dioxide content of starting roasted and ground coffee powder with a slightly better correlation for foam weight $\left(R^{2}=0.907\right)$. The foam volume ranged from about $2.5 \mathrm{~mL}$ for a $0.25 \mathrm{mg} \mathrm{CO} / \mathrm{g}$ coffee to about $12 \mathrm{~mL}$ for a $4.5 \mathrm{mg} \mathrm{CO} / \mathrm{g}$ coffee. Carbon dioxide content and foam volume correlation has been also observed by Foschia. ${ }^{46}$

These latter findings constitute a possible rationale to interpret previous data on espresso foam volume. As a matter of fact, factors like compaction, prolonged time between grinding and extraction, roasting degree, portion in espresso machine, percolation conditions, coffee species, etc. all remarkably affect the carbon dioxide content of the roast and coffee powder and then the foam volume.

\section{Foam Persistence}

Foam persistence is another property which has a special importance in the consumer appreciation of espresso. Foam should survive for at least a couple of minutes before breaking and leaving a first uncovered black spot on the surface of the beverage. ${ }^{9}$ Generally, the foam persistence is defined as the time that the liquid phase below the foam layer took to appear during cooling at room temperature in the same container used to measure foam volume. The first study on the subject ${ }^{3}$ reported foam persistence ranged from 6 to $40 \mathrm{~min}$. The factor positively affecting the foam volume such as the reduced time between roasting and extraction has been found to be negatively correlated to foam persistence. Similar results have been reported when coffee species have been claimed as having foam promoting factor, i.e., those that had higher foam volumes resulted in a lower foam persistence. ${ }^{17,36}$
Differently from foam volume, the persistence has not been found linearly correlated with the degree of roasting. ${ }^{23}$ As reported in Figure 7, for both arabica and robusta the persistence reached a maximum (33.9 and $48.6 \mathrm{~min}$, respectively) at a medium roasting degree over the range from light to very dark roast. The decline in foam persistence at higher roasting degree has been suggested to be related to thermally induced depolymerization of polysaccharide-derived Maillard reaction products with subsequent decrease in the viscosity of continuous phase. ${ }^{24}$

Process parameters such as water temperature and coffee portion seem to have not a significant influence on foam persistence whereas water pressure does. By increasing the latter from 7 to $11 \mathrm{~atm}$, foam persistence for pure arabica espresso $(7.5 \mathrm{~g}$ and $40 \mathrm{~mL})$ lasted between 24.7 and 30.0 min. $^{35}$

\section{Foam Consistence}

This physical property has been investigated less so few papers deal with it. Two different methods have been reported to determine foam consistence (also known as foam solidity). In the first one, foam consistence is assessed by measuring the time the foam bears a known weight (for instance $1.5 \mathrm{~g}$ ) of crystalline sucrose before penetrating the crema layer and for this reason is known as "sugar test". ${ }^{56}$ In the other method, similar in principle, the sugar is replaced by a generally laboratory-made apparatus with known weight and geometry (for instance $1.0 \mathrm{~g}$ and circular with a $2 \mathrm{~cm}$ diameter and a metal net in the center). ${ }^{23}$

By using the "sugar test" Severini et al. ${ }^{56}$ reported a foam consistence range from 0.5 to $14 \mathrm{~s}$. As in the case of foam volume, the prolonged time at ambient atmosphere between grinding and extraction is deleterious for the foam consistence: a storage of $36 \mathrm{~h}$ is sufficient to result in a foam consistence of only $0.5 \mathrm{~s}$. The range observed by Severini et al. ${ }^{56}$ has been substantially confirmed by other studies. ${ }^{15,16}$

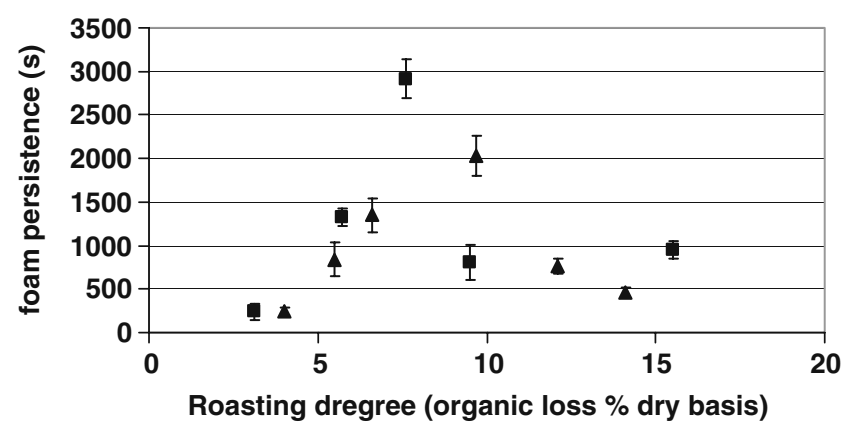

Fig. 7 Foam persistence (in seconds) as a function of Roasting degree (organic loss \% dry basis) after Nunes et al. ${ }^{23}$ Triangle pure Arabica; square pure Robusta 
It has also been found that there is high correlation between foam consistence and foam persistence independently on coffee species at different roasting degree. A maximum foam consistence has been observed in the medium roasting degree between a light roast to a very dark one. ${ }^{23}$

\section{Foaming and Antifoaming Mechanisms}

In spite of the fact that the carbon dioxide has been frequently suggested as the gas phase responsible of the espresso coffee foaming, the bubble formation mechanism has not been investigated in detail.

Fond ${ }^{22}$, in an attempt to interpret the dynamics of the transient phase of the espresso extraction, reported the possible role played by bicarbonate-carbonic acid equilibrium. The transient phase, well documented in literature $^{57,58}$ is the initial wetting stage of espresso brewing in which hot water fills into coffee particle voids while simultaneously inter- and intraparticle gas is pushed out of the coffee bed. In addition, mass transfer between coffee particles and water occurs simultaneously. The transient phase terminates when an equilibrium is reached and a steady state phase takes place (pressure and flow rate remain constant up to the end of percolation). In the transient phase, two processes can be distinguished:

1. flow rate and pressure increase, in accordance with Darcy's law

2. according to the pump characteristics, pressure increases while flow decreases in clear contradiction with classical hydraulics

The anomalous behavior of process 2, has been interpreted by Fond ${ }^{22}$ as the result of coffee bed compaction related to the bicarbonate ions present in the extraction fluid (water) and the displacement of its equilibrium according to the $\mathrm{pH}$ evolution in the course of brewing (from 7.0-7.5 to 5.5-5.0). In other words, process 2 was related to chemical reactions occurring at high temperature in the coffee bed resulting in its compaction through $\mathrm{CO}_{2}$ degassing. The latter, according to Fond ${ }^{22}$, "contributes to foam and emulsion generation".

This view overlooked the importance of the carbon dioxide already present in the roasted coffee, it doesn't explain the transient phase observed by using water at $4{ }^{\circ} \mathrm{C}{ }^{58}$ and it partially explains the role played by bicarbonate ions in the extraction fluid during espresso brewing. ${ }^{20,21}$ However, the study by Fond ${ }^{22}$ is the first one which put in evidence the relationship between carbon dioxide chemistry and foam generation.

Bubble formation in espresso brewing has been discussed by Navarini et al. ${ }^{6}$
It has been hypothesized that during espresso coffee brewing, the solubilization of carbon dioxide (present in the coffee bed) in water at high pressure and temperature lead to a supersaturation conditions in the beverage. In a usual coffee bar environment, $50 \mathrm{~mL}$ of water and $13.5 \mathrm{~g}$ of coffee are used for two cups of espresso. Thus, assuming about $4.5 \mathrm{mg} \mathrm{CO}_{2} / \mathrm{g}$ coffee, $61 \mathrm{mg}$ of carbon dioxide will be available to be solubilized. The resulting carbon dioxide concentration is approximately three times lower than $\mathrm{CO}_{2}$ solubility at a pressure of 9.2 bar and at a temperature of $100{ }^{\circ} \mathrm{C}$ but approximately two times higher than the solubility at a pressure of $1 \mathrm{bar}$ and at a temperature of $60^{\circ} \mathrm{C}$. This view is compatible with a foaming occurring through bubble formation by heterogeneous nucleation and bubble rise and this has been related to the effervescence normally observed immediately after espresso preparation. Micronic solid particles and sub-micronic cell-wall fragments, present in the beverage, may act as nucleation sites. Moreover, the small volume of an espresso beverage offers a limited length (about $1.5-2 \mathrm{~cm}$ in a standard espresso coffee cup) for bubble rise. These two conditions have been related to the size of the tiny bubbles characterizing espresso coffee foam.

From a quantitative point of view, the exercise proposed by Navarini et al. ${ }^{6}$ leads to a volume of $\mathrm{CO}_{2}$ available for foaming of about $7.6 \mathrm{~mL}$ (STP) per cup, a value within the reported foam volume range. This hypothesis has not yet been supported by further experimental evidences.

As far as the foam stability is concerned, it has been suggested that the relatively high temperature of the beverage may induce the reduction of the film thickness between bubbles by evaporation of water and this mechanism rather than disproportionation can play a role in foam collapse. ${ }^{6}$ Moreover, due to water evaporation, the surfactants concentration in the film increases and this generally results in a lowering of the surface tension. This effect is different between thin and thick part of the film resulting in a stretching which causes film instability. ${ }^{59}$

The thermal gradient at which the crema is subjected during its life may be relevant in interpreting the inverse correlation between foam volume and foam persistence. Too high of carbon dioxide availability, in view of its low solubility in hot water, can destabilize the foam that was just formed, whereas a lower carbon dioxide content in the bubbles may be retained for a long time in view of the viscosity increase of the continuous phase, on cooling: from about $0.50 \mathrm{mPa}$ s at $70{ }^{\circ} \mathrm{C}$ to $1.40 \mathrm{mPa} \mathrm{s}$ at $25^{\circ} \mathrm{C}^{41}$ Other foam instability sources can be hypothesized looking at the beverage chemistry.

The coexistence of high- and low-molecular-weight surfactants, for instance, in addition to the role played by $\mathrm{CO}_{2}$, can represent a rationale to interpret the debate over the foampromoting role of robusta coffee in espresso blending or the peculiar foam adhesion observed in pure robusta espresso. 
Destabilization of beer foam by lipids is widely documented and easily demonstrated. ${ }^{60,61}$ Free fatty acids, in particular, have been recognized as foam-negative materials depending on chain length and degree of saturation. The competition at the air/beverage interface of proteins able to stabilize the foam by forming a viscoelastic "skin" around the bubbles and free fatty acids, destabilizes the foam by reducing the strength of the adsorbed protein layer and increasing the probability of bubble rupture and coalescence. ${ }^{60}$ However, fatty acids with a chain length shorter than $\mathrm{C}_{12}$ are not surface active enough in the concentrations present in beer to compete with the proteins and destabilize the beer foam. $\mathrm{C}_{12}-\mathrm{C}_{14}$ fatty acids and the unsaturated $\mathrm{C}_{18: 1}$ and $\mathrm{C}_{18: 2}$ fatty acids destabilize foams by disrupting and weakening the adsorbed protein film whereas the saturated $\mathrm{C}_{16: 0^{-}}$ $\mathrm{C}_{18: 0}$ fatty acids probably act through the formation of hydrophobic aggregates that destroy the foam through a film-bridging mechanism. ${ }^{60}$

Lipids represent well-known antifoaming agents also in milk: the poor foaming behavior of whole milk as compared with skim milk is in accordance with practical experience. ${ }^{62}$ Skim milk tends to produce a lighter, airier foam over whole milk leading to differences in the rheology and in the visual texture of the corresponding foam. ${ }^{63}$ Other important antifoaming agents in milk are the products of lipolysis. Foaming of pasteurized milk is reduced when unesterified fatty acids are present. ${ }^{64}$ According to Buchanan, ${ }^{65}$ mono- and diacylglycerides, rather than free fatty acids, are responsible for this effect.

In espresso coffee, no detailed studies on the above subject have been produced. However the lipid content is remarkably higher than that of beer but remarkably lower or comparable than that of milk.

In particular, in a regular espresso $(25 \mathrm{~mL})$ the total lipids range from $45 \mathrm{mg}{ }^{4}$ to $146.5 \mathrm{mg}{ }^{17}$ for arabica and from $13.65 \mathrm{mg}^{4}$ to $119.25 \mathrm{mg}{ }^{17}$ for robusta. On average, pure arabica espresso contains a higher content of total lipids than robusta espresso, and therefore the probability of lipid induced foam destabilization is higher for arabica than for robusta. Since espresso coffee is well known to contains emulsified lipids, the lipid induced foam destabilization may also occur through oil spreading at air/ beverage interface ${ }^{66}$ and this is consistent with the lower surface tension generally observed in pure arabica espresso in comparison with pure robusta one. ${ }^{41}$

The only paper in which the lipid amount and composition of regular espresso brews prepared with the two different Coffea species has been compared reported a similar lipid content $(57 \mathrm{mg}$ and $58 \mathrm{mg}$ for arabica and robusta, respectively) but a polar lipid fraction (including phospholipids and free diterpene alcohols) three times higher in robusta than in arabica. ${ }^{67}$
Solid particles may destabilize the foam by film bridging but only in the case of hydrophobic particles through surface dewetting otherwise the film remains stable. The wetting nature of the solid particles present in espresso coffee has not yet been investigated. However, from one hand, the appreciated "tiger skin" effect observed in arabica espresso may suggest a foam stabilizing role of the solid particles, otherwise the antifoaming effect should be macroscopically rapid, ${ }^{68}$ from the other it is well known that roasting and some types of packaging induce the spreading of the oil on the coffee cell walls. ${ }^{1}$ In view of the previous discussion on the subject, the former hypothesis seems to be more credible.

The different foam adhesion observed between the two coffee species seems to reflect a different rate in the transition from liquid to dry foam. The arabica espresso foam rheology seems to be of the liquid-viscous type for a longer time; this system eventually drains and collapses leaving no residue whereas the solid-like nature of robusta espresso foam deriving from a higher drainage rate seems to be the prerequisite for adhesion.

In a study on foamed lipid emulsions, the physical state of the lipid phase from liquid to mostly solid has been investigated. ${ }^{69}$ It has been shown that solid lipid was destructive to the formation of the foam even though it subsequently proved to enhance the overall stability. The latter has been suggested to derive from colloidal interactions between dispersed lipid particles within the continuous phase resulting in slower foam drainage. It may be speculated that the different content, composition, and physical states of the lipid phase (including solid particles) in espresso prepared with different pure coffee species may affect foam drainage rate through colloidal interactions as observed in different systems. ${ }^{69}$ In this regard, it is interesting to underline that the viscosity of coffee oil at $92{ }^{\circ} \mathrm{C}$ is $7.8 \mathrm{mPa} \mathrm{s}$ whereas at $20^{\circ} \mathrm{C}$ is $70.6 \mathrm{mPa} \mathrm{s} .{ }^{1}$

From a chemical point of view, the hydroxy fatty acids suggested to negatively affect beer foam adhesion, have been reported to be originated by enzymatic and autooxidation of linoleic acid resulting in the formation of its hydroperoxides which are transformed into mono-, di-, and trihydoxyoctadecenoic acids. ${ }^{49}$ It is well documented that linoleic acid is the most abundant fatty acid in the green coffee triglycerides lipid fraction (arabica 52.2-54.3\%; robusta 43.9-49.3\%) and, upon roasting, it is the only one whose content decreases slightly as the roasting temperature increase. ${ }^{70}$

\section{Concluding Remarks}

The espresso coffee foam is a challenging topic for both the intrinsic complexity and the lack of scientific literature. It is clear that by adopting the "proper approach" a number of 
apparently unrelated phenomena may be interpreted and considered simply the results of Chemistry and Physics. The key to interpret the several factors affecting the crema, seems to be the carbon dioxide content of roasted coffee in addition to $\mathrm{CO}_{2}$ possibly present as bicarbonate ions in the water ingredient. Most of the data reported in the present review may suggest that espresso brewing can be described as "a quick way to transfer carbon dioxide from roasted and ground coffee to a small cup by means of hot water under pressure". This then leads to the facts that for espresso coffee, carbon dioxide has to be:

- generated by roasting

- maintained in the bean by proper packaging

- maintained in the ground coffee

- solubilized in water

- released into the beverage.

In this framework statements such as "any error in grinding or in percolation, in temperature or extraction level, has an immediate effect on denounced by the color, the texture and the persistence of the foam" or "the foam is the signature of a well-prepared espresso" can be well justified. In fact, foam volume, persistence, and consistence are the consequences of the carbon dioxide content originally present in the coffee. In addition to the importance of carbon dioxide in espresso coffee foam, we believe that carbon dioxide can play a role even from a taste point of view. This aspect has not yet been the subject of investigation.

From a chemical point of view, some foam-positive compounds have been isolated and characterized whereas foam-negative ones have been suggested but not yet sufficiently investigated, although the negative influence of lipids on foamability seems to be more than an isolated observation. Lipids and solid particles may affect the foam stability but this topic has to be investigated in more detail.

The role played by coffee species in espresso foam is not established and it cannot be considered a consolidated belief. As a matter of fact, the contrasting experimental results in the comparison (when performed) between arabica and robusta seem to suggest the statement like: "the high foamability of robusta" or "it is necessary to use robusta to increase the espresso foam" cannot be generalized. The interplay between carbon dioxide content and lipid content seems to be more relevant rather than coffee species as far as foamability and foam stability is concerned. However, the scarce literature on subject puts in evidence differences in color and foam texture between the foam obtained by the two species.

It is indisputable that up to now the espresso bubbles have been neglected from a scientific point of view, but the authors' opinion is that in addition to beer foam or other famous food foams the espresso crema may represent a good model system to merit attention in foam Science.
Of course, under the foam, the espresso has to be organoleptically excellent, without off-tastes and off-flavors and it has to ensure pleasure during and a smile after drinking.

Acknowledgment It is a pleasure to thanks all our friends and colleagues for the useful discussions, suggestions, and constructive criticisms given with warm enthusiasm. In particular Roberto Cappuccio, Michele Ferrari, Oriana Savonitti, Theodore P. Labuza, Massimo Barnabà, Marino Petracco, and Furio Suggi Liverani. We are indebted to Fabio Silizio for optical microscopy images and to illycaffè S.p.A (Trieste, Italy) for the photographic materials kindly provided.

Open Access This article is distributed under the terms of the Creative Commons Attribution Noncommercial License which permits any noncommercial use, distribution, and reproduction in any medium, provided the original author(s) and source are credited.

\section{References}

1. A. Illy, R. Viani (eds.), Espresso coffee: the science of quality, 2nd edn. (Elsevier Academic Press, London, 2005)

2. C.W. Bamforth, Foam: method, myth or magic? The Brewer 10, 396-399 (1995)

3. M. Dalla Rosa, M.C. Nicoli, C.R. Lerici, "Qualitative characteristics of espresso coffee with reference to percolation process" (in Italian). Ind. Aliment. 9, 629-633 (1986)

4. M. Petracco, "Physico-chemical and structural characterisation of espresso coffee brew" In: Proceedings of the 13th International Scientific Colloquium on Coffee, ASIC (Paipa). (ASIC, Paris, 1989) pp. 246-61

5. E. Dickinson, An introduction to food colloids (Oxford University Press, Oxford, 1992)

6. L. Navarini, M. Barnabà, F. Suggi Liverani, "Physicochemical characterization of the espresso coffee foam" In: Proceedings of the 21th International Scientific Colloquium on Coffee, ASIC (Montpellier). (ASIC, Paris, 2006) CD ROM

7. F. Bazzara, M. Bazzara, The espresso coffee production system (Edizioni 2000, Gorizia, 2004)

8. F. Suggi Liverani, L. Mastropasqua, F. Van Eeden, B. Dellapietra, "Method for extracting espresso coffee particularly from a cartridge with crema generating septum, and beverage obtainable from the method". (International Patent Application WO 2007/ 131559 A1, 2007)

9. M. Petracco, Beverage preparation: brewing trends for the new millennium, in Coffee Recent Developments, ed. by R.J. Clarke, O.G. Vitzthum (Blackwell Science, London, 2001)

10. R. Cappuccio, G.P. Cattaneo, G. Erbacci, U. Jocher, A parallel implementation of a cellular automata based model for coffee percolation. Parallel Comput. 27(5), 685-717 (2001)

11. E. Illy, The complexity of coffee. Sci. Am. 6, 92-98 (2002)

12. C.E. Barbera, "Gas-volumetric method for the determination of the internal non-odorous atmosphere of coffee beans" In: Proceedings of the $3 \mathrm{rd}$ International Scientific Colloquium on Coffee, ASIC (Montpellier). (ASIC, Paris, 1967) pp. 436-442

13. E. Shimoni, T.P. Labuza, Degassing kinetics and sorption equilibrium of carbon dioxide in fresh roasted and ground coffee. J. Food Process Eng 23, 419-436 (2000)

14. T.P. Labuza, C. Cardelli, B. Anderson, E. Shimoni, "Physical Chemistry of roasted and ground coffee: shelf life improvement for flexible packaging", In: Proceedings of the 19th International Scientific Colloquium on Coffee, ASIC, (Trieste). (ASIC, Paris, 2001) CD-ROM 
15. C. Severini, T. De Pilli, S. Romani, G.G. Pinnavaia, "Qualità characteristics of "espresso" coffee. A study performed through coffee shops" (in Italian). Ind. Aliment. 38, 12791284 (1999)

16. S. Romani, C. Severini, A.G. Fiore, G.G. Pinnavaia, "Quality of espresso coffee: a study performed through Italian coffee shops" In: Proceedings of the 20th International Scientific Colloquium on Coffee, ASIC, (Bangalore). (ASIC, Paris, 2004) CD ROM

17. L. Maetzu, S. Andueza, C. Ibanez, M. Paz de Pena, J. Bello, C. Cid, Multivariate methods for characterization and classification of espresso coffees from different botanical varieties and types of roast by foam, taste and mouthfeel. J. Agric. Food Chem. 49, 4743-4747 (2001)

18. C.J. Clarke, R. Macrae, Coffee volume 2: technology (Elsevier Applied Science, New York, 1987)

19. B.A. Anderson, E. Shimoni, R. Liardon, T.P. Labuza, "The diffusion kinetics of carbon dioxide in fresh roasted and ground coffee". J. Food Eng. 59, 71-78 (2003)

20. L. Navarini, D. Rivetti, Water quality for Espresso coffee. Food Chem. 122, 424-428 (2010)

21. D. Rivetti, L. Navarini, R. Cappuccio, A. Abatangelo, M. Petracco, F. Suggi-Liverani, "Effects of water composition and water treatment on espresso coffee percolation" In: Proceedings of the 19th International Scientific Colloquium on Coffee, ASIC, (Trieste). (ASIC, Paris, 2001) CD-ROM

22. O. Fond, "Effect of water and coffee acidity on extraction dynamics of coffee bed compaction in espresso type extraction", In: Proceedings of the 16th International Scientific Colloquium on Coffee, ASIC (Kyoto). (ASIC, Paris, 1995) pp. 413-420

23. F.M. Nunes, M.A. Coimbra, A.C. Duarte, L. Delgadillo, Foamability, foam stability, and chemical composition of espresso coffee as affected by the degree of roast. J. Agric. Food Chem. 45, 3238-3243 (1997)

24. F.M. Nunes, M.A. Coimbra, Influence of polysaccharide composition in foam stability of espresso coffee. Carbohydr. Polym. 37, 283-285 (1998)

25. L. Navarini, R. Gilli, V. Gombac, A. Abatangelo, M. Bosco, R. Toffanin, Polysaccharides from hot water extracts of roasted Coffea arabica beans: isolation and characterization. Carbohydr. Polym. 40, 71-81 (1999)

26. L. Navarini, M. Petracco, "Heavily foaming coffee fraction and process for its manufacture" European Patent Application, EP 1 021957 A1 (1999)

27. M. Petracco, L. Navarini, A. Abatangelo, V. Gombac, E. D'Agnolo, F. Zanetti, "Isolation and characterization of a foaming fraction from hot water extracts of roasted coffee",In: Proceedings of the. 18th International Scientific Colloquium on Coffee, ASIC (Helsinki). (ASIC, Paris, 1999) pp. 95-105

28. L. Piazza, J. Gigli, A. Bulbarello, Interfacial rheology study of espresso coffee foam structure and properties. J. Food Eng. 84, 420-429 (2008)

29. D. Rossetti, G.E. Yakubov, J.R. Stokes, A.M. Williamson, G.G. Fuller, Interaction of human whole saliva and astringent dietary compounds investigated by interfacial shear rheology. Food Hydrocolloids 22, 1068-1078 (2008)

30. R. Saliba, M.J. Ayoub, "Des proteins fortement moussantes dans le café torrefie" (in French). Sciences des Aliments 23, 249-263 (2003)

31. A. D'Agostina, G. Boschin, F. Bacchini, A. Arnoldi, Investigations on the high molecular weight foaming fractions of espresso coffee. J. Agric. Food Chem. 52, 7118-7125 (2004)

32. V. Aroulmoji, F. Hutteau, M. Mathlouthi, D.N. Rutledge, Hydration properties and the role of water in taste modalities of sucrose, caffeine and sucrose-caffeine mixtures. J. Agric. Food Chem. 49, 4039-4045 (2001)

33. R. Douillard, V. Aguié-Béghin, "Surface active molecules and foam properties of some beverages", in Proceedings of the
European Workshop on Recent Advances in Melanoidins Research. (Madrid, 2002) pp. 14

34. A. Illy, R. Viani (eds.), Espresso Coffee: The Chemistry of Quality (Elsevier Academic Press, London, 1995)

35. S. Andueza, L. Maeztu, B. Dean, M.P. de Pena, J. Bello, C. Cid, Influence of water pressure on the final quality of arabica espresso coffee. Application of multivariate analysis. J. Agric. Food Chem. 50, 7426-7431 (2002)

36. S. Andueza, L. Maeztu, L. Pascual, C. Ibanez, M.P. de Pena, C. Cid, Influence of extraction temperature on the final quality of espresso coffee. J. Sci. Food Agric. 83, 240-248 (2003)

37. S. Andueza, M.A. Vila, M.P. de Pena, C. Cid, Influence of coffee/ water ratio on the final quality of espresso coffee. J. Sci. Food Agric. 87, 586-592 (2007)

38. L. Navarini, M. Ferrari, F. Suggi Liverani, L. Liggieri, F. Ravera, Dynamic tensiometric characterization of espresso coffee beverage. Food Hydrocolloids 18, 387-393 (2004)

39. A. Kabalnov, J. Weers, R. Arlauskas, T. Tarara, Phospholipids as emulsion stabilizers. 1. Interfacial-tension. Langmuir 11, 29662974 (1995)

40. M. Ferrari, L. Navarini, L. Liggieri, F. Ravera, F. Suggi Liverani, Interfacial properties of coffee-based beverages. Food Hydrocolloids 21, 1374-1378 (2007)

41. L. Navarini, R. Cappuccio, F. Suggi Liverani, "The body of the espresso coffee: the elusive importance" In: Proceedings of the 20th International Scientific Colloquium on Coffee, ASIC, (Bangalore). (ASIC, Paris, 2004) CD ROM

42. C.E. Christersson, R.G. Dunford, P.-O. Glantz, R.E. Baier, "Effect of critical surface tension on retention of oral microorganisms". Scand. J. Dent. Res. 97, 247-256 (1989)

43. P.-O. Glantz, Interfacial phenomena in the oral cavity. Colloids Surf. A 123-124, 657-670 (1997)

44. A. Vissink, H.P. De Jong, H.J. Busscher, J. Arends, E.J. Gravenmade, Wetting properties of human saliva and saliva substitutes. J. Dent. Res. 65, 1121-1124 (1986)

45. M. Daglia, R. Tarsi, A. Papetti, P. Grisoli, C. Da Carro, C. Pruzzo, G. Gazzani, Antiadhesive effect of green and roasted coffee on Streptococcus mutans adesive properties on saliva-coated hydroxyapatite beads. J. Agric. Food Chem. 50, 1225-1229 (2002)

46. V. Foschia, "La crema del caffè espresso: caratterizzazione chimicofisica" (in Italian) (Università di Udine, Tesi di Laurea, 2008)

47. C.W. Bamforth, The foaming properties of beer. J. Inst. Brew. 91, 370-383 (1985)

48. L.R. Bishop, A.L. Whitear, W.R. Inman, A scientific basis for beer foam formation and cling. J. Inst. Brew. 80, 68-80 (1974)

49. N. Kobayashi, S. Segawa, S. Umemoto, H. Kuroda, H. Kaneda, Y. Mitani, J. Watari, M. Takashio, A new method for evaluating foam-damaging effect by free fatty acids. J. Am. Soc. Brew. Chem. 60, 37-41 (2002)

50. C. Fischer, H.K. Cammenga, "When are coffee beans just right? Development of physico-chemical properties during roasting", In: Proceedings of the 19th International Scientific Colloquium on Coffee, ASIC, (Trieste). (ASIC, Paris, 2001) CD-ROM

51. B.P. Binks, Particles as surfactants-similarities and differences. Curr. Opin. Colloid Interface Sci. 7, 21-41 (2002)

52. F. Silizio, “Coffee foam”, IC Biolab, Internal Report nº03/2008 (2008).

53. S.J. Neethling, H.T. Lee, J.J. Cilliers, "The dispersion of particles within foams" in Proceedings of the XXI Int. Congress of Technical and Applied Mechanics. (Warsaw, Poland, 2004)

54. S. Andueza, L. Maeztu, M.P. de Pena, C. Cid, "Influence of extraction temperature on the final quality of colombian coffee cups" In: Proceedings of the 19th International Scientific Colloquium on Coffee, ASIC, (Trieste). (ASIC (Association Scientifique Internationale du Café), Paris, 2001) CD-ROM 
55. R.J. Pugh, Foams and Foaming, in Handbook of Applied Surface and Colloid Chemistry, ed. by K. Holmberg (Wiley, Chichester, 2001). Ch 25

56. C. Severini, S. Romani, G.G. Pinnavaia, "Investigation into the quality of espresso coffee" (in Italian). Ind. Aliment. 36, 12-16 (1997)

57. E. Illy, T. Bullo, "Considérations sur le procédé d'extraction (préparation de la boisson)" (in French) In: Proceedings of the 1st International Scientific Colloquium on Coffee. ASIC, Paris. Café Cacao Thé, 7, 177-181 (1963)

58. M. Petracco, F. Suggi Liverani, "Espresso coffee brewing dynamics: development of mathematical and computational models", In: Proceedings of the 15th International Scientific Colloquium on Coffee, ASIC, (Montpellier). (ASIC, Paris, 1993) pp 702-711.

59. A. Prins, Principles of Foam Stability, in Advances in Food Emulsions and Foams, ed. by E. Dickinson, G. Stainsby (Elsevier Applied Science, Essex, 1988), p. 91

60. P.J. Wilde, F.A. Husband, D. Cooper, M.J. Ridout, E.N.C. Mills, R.E. Muller, Destabilization of beer foams by lipids: structural and Interfacial Effects. J. Am. Soc. Brew. Chem. 61, 196-202 (2004)

61. K.H. Dickie, C. Cann, E.C. Norman, C.W. Bamforth, R.E. Muller, Foam-negative materials. J. Am. Soc. Brew. Chem. 59, 17-23 (2001)

62. M. Anderson, B.E. Brooker, Dairy Foams, in Advances in Food Emulsions and Foams, ed. by E. Dickinson, G. Stainsby (Elsevier Applied Science, Essex, 1988), p. 221
63. C. Rampini, N. Innocente, L. Navarini, F. Suggi Liverani, "Aspects of milk and milk foams on dairy based espresso coffee hot drinks", In: Proceedings of the 21th International Scientific Colloquium on Coffee, ASIC, (Montpellier). (ASIC, Paris, 2006) CD ROM

64. H.C. Deeth, R.A.D. Smith, Lipolysis and other factors affecting the steam frothing capacity of milk. Aust. J. Dairy Technol. 38, 14-19 (1983)

65. R.A. Buchanan, Lipolysis and the frothing of milk-steam frothing test. Aust. J. Dairy Technol. 20, 62-66 (1965)

66. E.P. Schokker, M.A. Bos, A.J. Kuijpers, M.E. Wijnen, P. Walstra, Spreading of oil from protein stabilized emulsions at air/water interfaces. Colloids and Interfaces B: Biointerfaces 26, 315-327 (2002)

67. W.M.N. Ratnayake, R. Hollywood, E. O'Grady, B. Stavric, Lipid content and composition of coffee brews prepared by different methods. Food Chem. Toxic. 31, 263-269 (1993)

68. P.A. Kralchevsky, K.D. Danov, N.D. Denkov, Chemical physics of colloid systems and interfaces, in Handbook of Surface and Colloid Chemistry, ed. by K.S. Birdi (CRC Press, New York, 2002)

69. G.M. Pilhofer, H. Lee, M.J. McCarthy, P.S. Tong, J.B. German, Functionality of milk fat in foam formation and stability. J. Dairy Sci. 77, 55-63 (1994)

70. K. Speer, I. Kolling-Speer, Lipids, in Coffee recent developments, ed. by R.J. Clarke, O.G. Vitzthum (Blackwell Science, London, 2001) 